\title{
Obesity in Elderly Subjects
}

\section{In sheep's clothing perhaps, but still a wolf!}

ETTY OSHeR, MD

Naftali STERN, MD

A lthough the negative impact of high BMI on the risk of death from allcause mortality is now well established, there is an apparent decline in the relative added risk of obesity with increasing age $(1,2)$. This has led some experts to conclude that obesity should not necessarily be viewed as a disease in individuals older than 55 years. If such shift in the approach to adiposity during the latter phases of life is prematurely accepted, it may not only discourage attempted weight loss in older subjects, but also promote nutritional and lifestyle indulgence, which is presently difficult enough to overcome. It is the purpose of the present commentary to briefly outline the full spectrum of obesity-related hardships in the elderly. In our opinion, obesity-induced complications amount to real disease, which gravely affects quality of life and limits effective lifespan.

\section{OBESITY, HYPERTENSION, DIABETES, AND THE METABOLIC SYNDROME IN ADVANCED ACE - The incidence} of hypertension, diabetes, and the metabolic syndrome intensifies with age, and aging per se is closely linked to increased prevalence of most of the abnormalities contributing to the metabolic syndrome (3). The incidence of the metabolic syndrome rises with increasing BMI, and a broader waist circumference is more common in men older than 65 years than in younger age-groups (3). The occurrence of the metabolic syndrome reaches peak levels in the 6th decade for men and the 7 th decade for women, and a decline is noted only in the 8th decade for men and for some women in different ethnic groups (3). As recently outlined by the American Heart Association Professional Education Committee of the Council for High Blood Pressure Research, older age and obesity are two of the most powerful risk factors for uncontrolled hypertension (4), and high blood pressure, in turn, is a major determinant of mortality and stroke incidence, particularly in senior years. BMI and abdominal obesity are significantly and independently associated with an increase in the prevalence of type 2 diabetes and hypertension, and obesity contributes to the development of hypertension in diabetes in all ages, including old age (5). Hence, separation of abdominal adiposity from its closest sequels, i.e., the metabolic syndrome, hypertension, and diabetes, is somewhat artificial, especially later in life. Adiposity strongly influences these risk factors, which, with the passage of time, may directly dominate the occurrence of complications. The strongest support for such a sequence of events is the fact that attempted weight loss is associated with lower all-cause mortality, regardless of age (6).

\section{OBESITY AND MORTALITY IN OLDER SUBJECTS - Despite} claims that obesity is not harmful in older individuals, several large-scale studies, such as the 10-year follow-up of the National Institutes of Health-AARP cohort (1), indicated that both overweight and obesity, at all ages and in both sexes, particularly in those individuals who had never smoked and who had no history of disease, are linked to increased mortality $(1,2,7)$. Although the relative escalation

From the Institute of Endocrinology, Metabolism, and Hypertension, Tel Aviv-Sourasky Medical Center and Sackler Faculty of Medicine, Tel Aviv University, Tel Aviv, Israel.

Corresponding author: Naftali Stern, stern@tasmc.health.gov.il.

The publication of this supplement was made possible in part by unrestricted educational grants from Eli Lilly, Ethicon Endo-Surgery, Generex Biotechnology, Hoffmann-La Roche, Johnson \& Johnson, LifeScan, Medtronic, MSD, Novo Nordisk, Pfizer, sanofi-aventis, and WorldWIDE.

DOI: $10.2337 / \mathrm{dc09-S347}$

(C) 2009 by the American Diabetes Association. Readers may use this article as long as the work is properly cited, the use is educational and not for profit, and the work is not altered. See http://creativecommons. org/licenses/by-nc-nd/3.0/ for details. in risk associated with a high BMI may decline with advancing age, the absolute rise in mortality rates associated with a high BMI is still much greater in elderly subjects, simply due to increased death rates in this age range (2). This relationship may no longer exist for the very old, in whom mortality rates may be driven by malignancy or aging of the cardiovascular tree that evolved throughout life. In this extreme age range, body weight most likely reflects both overall health status and the process of aging-induced weight loss. However, this cannot be extrapolated to the older population at large or viewed as evidence that high BMI is generally beneficial in the 6th to the 8th decades of life.

The true impact of overweight and obesity on mortality may be obscured by confounding factors. For example, reverse causation induced by preexisting chronic disease and inadequate control for smoking status can mask the effect of obesity through the excessive death risk caused by these low BMI-associated conditions. In some distinct diseases of the elderly, such as Alzheimer's disease (8) or Parkinsonism (9), weight loss may precede the time of diagnosis by years, thus causing further false overrepresentation of morbidity and mortality in the low weight range.

Finally, cumulative attrition of the most vulnerable fraction of the obese population brought about by premature mortality of those subjects who do not survive the late-midlife years leaves only the most biologically advantaged obese survivors for "nonbiased" epidemiological analysis of obesity in advanced years. If one accepts that obesity increases mortality in younger years, attempted comparison between age-matched obese and lean humans in the older age inevitably leads to the study of two highly unequal cohorts of which only one has been subjected to the Darwinian process of obesity-related attrition.

\section{heALTH ADVANTAGES OF OLDER OBESE SUBJECTS: RESILIENT BONES AND THE "OBESITY PARADOX" - Reex-} amination of the impact of obesity on 
health in older individuals disclosed two potential benefits of weight excess: decreased osteoporosis and better survival of obese subjects with certain health hazards, known as the "obesity paradox." Obesity, linked to increased bone mineral density, is thus far uncontested, as is the fact that this also translates into a lower rate of hip fractures in elderly obese subjects (10). The latter may reflect not only greater bone resilience, but also improved cushioning by adipose tissue during falls. An important emerging exception to this general protective effect of obesity on bone is the recent finding that although men and women with the metabolic syndrome do indeed enjoy better total hip and femoral neck bone mineral density in a cross-sectional analysis, these associations do not translate to improved clinical outcome. In fact, incident clinical fractures were 2.6 times more likely to occur in subjects with the metabolic syndrome compared with participants without the metabolic syndrome after an average follow-up of 2 years (11)

The "obesity paradox" refers to the unexpected findings that obese subjects seem to fare better than, or at least as well as, their normal- or low-weight counterparts in terms of mortality rates in the context of conditions, such as coronary artery disease in hypertensive subjects, congestive heart failure, chronic kidney disease, hemodialysis, postcoronary revascularization, and some instances of non-ST segment elevation in myocardial infarction $(12,13)$. Currently, it is unclear whether or not all these different situations that share some common, yet unidentified, underlying mechanism are related to obesity itself, or rather reflect nutritional status or reserve, and/or possibly coexisting medical therapy. It remains uncertain how older age interacts with these protective effects of excess adiposity. Additionally, obesity is not a general "savior" in acute medical conditions. Hence, this interesting and potentially critical phenomenon remains presently enigmatic, requiring case- and age-specific in-depth examination. As an example of this effect, some 20 years ago, obesity in the elderly was actually linked to the twofold increase of postmyocardial infarction and inhospital mortality in subjects $>65$ years (14). Has the obese phenotype been changed by the environment, or chronic medical therapy, or rather, have advances in the quality of critical care preferentially affected the obese?

\section{OBESITY AND CARDIOVASCULAR DISEASE}

IN THE ELDERIY - The cardiometabolic complications of obesity have been generally linked to central adiposity, but in many reports, obesity is quantified in terms of BMI alone, rather than waist circumference, which may potentially mask the association of abdominal fat and cardiovascular disease and events. Nevertheless, a body of evidence indicates that obese older subjects are more prone to cardiovascular morbidity. In the Health Professionals' Follow-up Study, men aged 65 years or older, with a waist-to-hip ratio of $\geq 0.98$, had a 2.76 -fold increased risk for coronary heart disease (CHD), even after adjustment for BMI and other cardiac risk factors (15). In the Physicians' Health Study (a randomized trial of aspirin and $\beta$-carotene among 22,071 apparently healthy U.S. male physicians, aged 40-84 years at baseline), abdominal adiposity, whether measured by waist-to-hip ratio or waist circumference, was associated with a modest elevation in the risk of CHD in both middle-aged and older men. Of particular note in this study is the finding that age did not significantly modify the relationship between either measure of abdominal adiposity and risk of CHD (16). In a Chinese cohort of 67,334 women, aged 40-70 years, who had no prior history of $\mathrm{CHD}$, stroke, or cancer at recruitment into the study, in the course of a mean follow-up of 2.5 years $(168,164$ person-years), waist-to-hip ratio was positively associated with the risk of $\mathrm{CHD}$ in both younger and older women, while other anthropometrics, including BMI, were related to $\mathrm{CHD}$ risk primarily among younger women (17). In a prospective study of 516 Brazilian women, aged 60-84 years, who were followed up for an average period of 6.6 years, the presence of the metabolic syndrome and high waist-to-hip ratio was associated with increased cumulative risk (odds ratio 1.66 and 1.72 , respectively) of stroke, myocardial infarction, evidence of coronary artery disease, or cardiovascular death (18). In the Epidemiologic Follow-Up Study of the First National Health and Nutrition Examination Survey (NHANES I), 1,259 Caucasian women aged 65-74 years with BMI $\geq 29 \mathrm{~kg} / \mathrm{m}^{2}$ showed $50 \%$ increased risk of CHD in the course of a mean follow-up period of 14 years, which was 2.5fold higher than in women with BMI of $23-24 \mathrm{~kg} / \mathrm{m}^{2}$ (19). A Swedish study of 70-year-old subjects, initially free from CHD, found that the 15-year risk- adjusted incidence of CHD was increased by larger waist circumference and BMI in males but not in females (20). In a U.S. cohort of 4,968 older ( $\geq 65$ years) men and women from the Cardiovascular Health Study followed up for 9 years, the risks of myocardial infarction or stroke did not differ in the overweight range of $25-29.99 \mathrm{~kg} / \mathrm{m}^{2}$, thus suggesting that a BMI cutoff point of $25 \mathrm{~kg} / \mathrm{m}^{2}$ may be overly restrictive for the elderly (21). Overall, these data support an association between adiposity, particularly central adiposity, as assessed by anthropometric measurements, and increased propensity for cardiovascular disease, predominantly CHD.

\section{OBESITY AND THE INCIDENCE OF STROKE IN OLder SUBJECTS - Association} between obesity and stroke in advanced age has been inconsistent and may be sexrelated. The Canadian Cardiovascular Health study did not find obesity to be a predisposing factor for stroke in older subjects (21). Conversely, the Honolulu Heart Program, which over a 22-year period prospectively followed up a cohort of 1,163 nonsmoking men aged 55-68 years, found that the rate of thromboembolic stroke rose significantly with increasing levels of BMI (22). In subjects from the Framingham Offspring Study aged 50-81 years, the 10-year population attributable risk of stroke was greater for the metabolic syndrome than for diabetes, particularly in women ( 27 vs. $5 \%$ ), owing to its greater prevalence of the metabolic syndrome in the general population (23). Obesity did not affect stroke rates in Korean men (24). A Spanish stroke registry of 2,000 consecutive stroke patients identified obesity as one significant predictor of stroke in women (mean age 75 years), but not in men (25). A similar identification of obesity as a risk factor for atherothrombotic brain infarction in older female but not male subjects was also reported by Aronow et al. (26). In a post hoc analysis of the Systolic Hypertension in the Elderly (SHEP) trial, the lowest BMI quintile was associated with increased occurrence of stroke rather than obesity (27), but after introduction of control of multiple confounders, the relation of BMI to death or stroke rate in the placebo group became insignificant. Overall, we interpret this mixed outcome of the attempt to clarify whether obesity is a contributor to the etiology of stroke in the elderly as a simple reflection of the 
dominant roles of hypertension, including obesity-related hypertension, as well as adiposity-related diabetes in this setting.

\section{OBESITY MAY BE A PREDISPOSING FACTOR FOR REDUCED COCNITIVE SKILLS AND ALZHEIMER'S}

DISEASE - In the otherwise healthy older population, the combination of an expansive waist circumference or BMI, with high systolic or diastolic blood pressure, was linked to a modest decrease in performance on tests of motor speed, manual dexterity, and executive function (28). The Framingham Heart Study comprising male participants (age range 55-88 years) followed up over a period of 18 years revealed that obesity had an adverse effect on cognitive performance (29). In a Swedish cohort of nondemented adults who were followed up from age 70 to 88 years, high body mass was linked to increased propensity for dementia (30). The association appeared to be so profound that the risk for Alzheimer's disease increased by 36\% for every BMI unit at the age of 70 years. In population studies, such linkage is subject to the confounding effect of the natural history of Alzheimer's disease often characterized by weight loss, which precedes the diagnosis of this condition (8). A recent meta-analysis of the literature suggested the existence of a significant U-shaped association between BMI and Alzheimer's disease. The pooled effects of obesity on incident Alzheimer's disease and vascular dementia revealed a 1.80- and 1.73-fold increase in risk, which was particularly evident in studies with long follow-up $(>10$ years) and young baseline age $(<60$ years). Of particular note was the finding in all the studies reviewed that weight gain and large waist circumference, or skinfold thickness, increased the risk of dementia (31).

\section{OBESITY, MOBILITY, AND PHYSICAL INDEPENDENCE IN OLDER SUBJECTS - Low lev-}

els of spontaneous physical activity is a major predictor of adipose tissue accumulation in humans, and total body movement, most of which is related to ambulation, is negatively correlated with fat mass (32)

Physical inactivity, in turn, has rapid profound effects on skeletal muscle metabolism. Unlike the common association of obesity with increased lean body mass and muscle volume in young adults, obese older individuals often develop sarcopenia, reflected by reduction in lean body mass. Impaired mobility in older obese individuals is therefore hardly surprising. A recent study of 2,982 subjects, aged 70-79 years, followed up for 6.5 years, revealed that high adiposity increased the risk of new-onset mobility limitation by $40-50 \%$ (33). A crosssectional study of 92 monozygotic and 104 dizygotic community-living pairs of twin sisters (aged 63-76 years) reared together found an inverse association between adiposity and mobility that was mostly due to the effect of shared genes (34). Larger waist circumference was a powerful predictor of new-onset disability 2 years later, associated with a 2.17 fold increase in the adjusted risk of mobility disability and a 4.77-fold higher adjusted risk of agility disability for men in the highest quintile compared with those in the lowest quintile (35).

\section{OBESITY AND FRAILTY IN}

OLDER ACE - Obesity clearly exacerbates the age-related decline in physical function and causes frailty in older individuals. Frailty in older obese individuals may be related to the insulin resistance and inflammation that often accompany obesity (36). This is reflected by selfreported impairment in activities of daily living in the older obese individual, limitations in mobility and decreased physical performance (as detailed in the former segment), increased risk for functional decline, and a higher rate of nursing home admissions (35,37-39). Of particular significance in establishing a cause-andeffect relationship between obesity and frailty is the recent report that weight loss and exercise can ameliorate frailty in older obese adults (40).

\section{OBESITY AND \\ DEGENERATIVE OSTEOARTHRITIS IN ADVANCED SENIOR}

YEARS - Increased body mass has a negative impact on weight-bearing joints, and knee osteoarthritis is particularly common in obese men (58\%) and women (68\%) by the age of $\geq 65$ years (41). The physical limitation caused by this condition is widely appreciated, but less attention is paid to the inevitable impact on pain and chronic overconsumption of analgesics that often underlie the development of drug-resistant hypertension and incipient nephropathy.

\section{SEXUAL DYSFUNCTION AND OBESITY IN OLDER} SUBJECTS - A recent study indicated that central obesity, assessed by several anthropometric indicators, is associated with the presence of erectile dysfunction in men $>60$ years, but not in younger men (42). Although age appeared to be the major determinant of erectile dysfunction in NHANES, obesity had an independent contributory effect, increasing the odds ratio for impotence by 1.6 (43). In a cross-sectional analysis of men $>50$ years of age in the U.S. Health Professionals' Study, obesity independent of other confounding factors increased the risk of erectile dysfunction by 30\% (44).

\section{URINARY INCONTINENCE IN OLDER OBESE}

SUBJECTS - Obesity is a recognized contributing factor to urinary incontinence in older women and men (45). Although the precise underlying mechanism(s) is unclear, the apparent excessive weight and pressure applied on the bladder by the increased intra-abdominal fat mass appears to be a reasonable contributor to this complication.

\section{OBESITY AND RENAL DISEASE IN OLDER}

SUBJECTS - The prevalence of renal failure increases with age, and obesity is a significant risk factor for end-stage renal disease (46). Compiled data from 57 prospective studies clearly links obesity to mortality of kidney disease, such that death of renal disease increased progressively with BMI (47). Although agespecific trends were not provided, hazard ratio in this analysis was based on subjects up to the age of 79 years. A recent report indicated that increased waist-to-hip ratio was a significant and independent predictor of chronic renal disease in elderly Taiwanese (48). In a cross-sectional study in African Americans, increasing age and waist circumference were associated with increased chronic kidney disease (49). Collectively, this information suggests that obesity, particularly abdominal adiposity, imparts a negative effect on renal disease in the older population.

CONCLUSIONS - Obesity per se continues to contribute to mortality in advanced years. However, even if mortality is conceded to be unrelated to obesity at an older age, the unaffected risk of death remains, at best, an imperfect descriptive 
measure of a disease spread over multiple years of life. Obese, or overweight, older subjects with such presumed unimpaired longevity are nevertheless more likely to have hypertension and diabetes; develop coronary artery disease and possibly stroke; experience erectile dysfunction; suffer from accelerated loss of cognitive function, incontinence, frailty, osteoarthritis, and functional disability; and are dependent on others. The clustering of so many well-defined ailments resulting from, or associated with, obesity, particularly in older subjects, is impressive enough to view obesity as a real primary disease that requires attention and medical care.

Acknowledgments - No potential conflicts of interest relevant to this article were reported.

\section{References}

1. Adams KF, Schatzkin A, Harris TB, Kipnis V, Mouw T, Ballard-Barbash T, Hollenbeck A, Leitzmann MF. Overweight, obesity, and mortality in a large prospective cohort of persons 50 to 71 years old. N Engl J Med 2006;355:763-778

2. Stevens J, Cai J, Pamuk ER, Williamson DF, Thun MJ, Wood JL. The effect of age on the association between body mass index and mortality. N Engl J Med 1998; 338:1-7

3. Park YW, Zhu S, Palaniappan L, Heshka S, Carnethon MR, Heymsfield SB. The metabolic syndrome: prevalence and associated risk factor findings in the US population from the Third National Health and Nutrition Examination Survey, 1988-1994. Arch Intern Med 2003; 163:427-436

4. Calhoun DA, Jones D, Textor S, Goff DC, Murphy TP, Toto RD, White A, Cushman WC, White W, Sica D, Ferdinand K, Giles TD, Falkner B, Carey RM; American Heart Association Professional Education Committee. Resistant hypertension: diagnosis, evaluation, and treatment: a scientific statement from the American Heart Association Professional Education Committee of the Council for High Blood Pressure Research. Circulation 2008;117:e510 e526

5. Kabakov E, Norymberg C, Osher E, Koffler M, Tordjman K, Greenman Y, Stern N. Prevalence of hypertension in type 2 diabetes mellitus: impact of the tightening definition of high blood pressure and association with confounding risk factors. J Cardiometab Syndr 2006;1:95-101

6. Gregg EW, Gerzoff RB, Thompson TJ, Williamson DF. Intentional weight loss and death in overweight and obese U.S. adults 35 years of age and older. Ann Intern Med 2003;138:383-389

7. Flegal KM, Graubard BI, Williamson D, Gail MH. Excess deaths associated with underweight, overweight, and obesity. JAMA 2005;293:1861-1867

8. Atti AR, Palmer K, Volpato S, Winblad B, De Ronchi D, Fratiglioni L. Late-life body mass index and dementia incidence: nineyear follow-up data from the Kungsholmen Project. J Am Geriatr Soc 2008;56: 111-116

9. Logroscino G, Sesso HD, Paffenbarger RS Jr, Lee IM. Body mass index and risk of Parkinson's disease: a prospective cohort study. Am J Epidemiol 2007;166:1186-1190

10. DiPietro L, Welch GA, Davis DR, Drane JW, Macera CA. Body mass and risk of hip fracture among a national cohort of postmenopausal white women: a reanalysis. Obes Res 1993;1:357-363

11. Von Muhlen D, Safii S, Jassal SK, Svartberg J, Barrett-Connor E. Associations between the metabolic syndrome and bone health in older men and women: the Rancho Bernardo Study. Osteoporos Int 2007;18:1337-1344

12. Uretsky S, Messerli FH, Bangalore S, Champion A, Cooper-Dehoff RM, Zhou Q, Pepine CJ. Obesity paradox in patients with hypertension and coronary artery disease. Am J Med 2007;120:863-870

13. Beddhu $\mathrm{S}$. The body mass index paradox and an obesity, inflammation, and atherosclerosis syndrome in chronic kidney disease. Semin Dial 2004;17:229-232

14. Hoit BD, Gilpin EA, Maisel AA, Henning $\mathrm{H}$, Carlisle J, Ross J Jr. Influence of obesity on morbidity and mortality after acute myocardial infarction. Am Heart J 1987; 114:1334-1141

15. Rimm EB, Stampfer MJ, Giovannucci E, Ascherio A, Spiegelman D, Colditz GA, Willett WC. Body size and fat distribution as predictors of coronary heart disease among middle-aged and older US men. Am J Epidemiol 1995;141:1117-1127

16. Rexrode KM, Buring JE, Manson JE. Abdominal and total adiposity and risk of coronary heart disease in men. Int J Obes Relat Metab Disord 2001;25:1047-1056

17. Zhang X, Shu XO, Gao YT, Yang G, Matthews CE, Li Q, Li H, Jin F, Zheng W. Anthropometric predictors of coronary heart disease in Chinese women. Int J Obes Relat Metab Disord 2004;28:734740

18. Cabrera MA, Gebara OC, Diament J, Nussbacher A, Rosano G, Wajngarten M. Metabolic syndrome, abdominal obesity, and cardiovascular risk in elderly women. Int J Cardiol 2007;114:224-229

19. Harris TB, Ballard-Barbasch R, Madans J, Makuc DM, Feldman JJ. Overweight, weight loss, and risk of coronary heart disease in older women: the NHANES I Epidemiologic Follow-Up Study. Am J Epidemiol 1993;137:1318-1327
20. Dey DK, Lissner L. Obesity in 70-year-old subjects as a risk factor for 15-year coronary heart disease incidence. Obes Res 2003;11:817-827

21. Janssen I. Morbidity and mortality risk associated with an overweight BMI in older men and women. Obesity (Silver Spring) 2007; 15:1827-1840

22. Abbott RD, Behrens GR, Sharp DS, Rodriguez BL, Burchfiel CM, Ross GW, Yano K, Curb JD. Body mass index and thromboembolic stroke in nonsmoking men in older middle age: the Honolulu Heart Program. Stroke 1994;25:2370-2376

23. Najarian RM, Sullivan LM, Kannel WB, Wilson PW, D'Agostino RB, Wolf PA. Metabolic syndrome compared with type 2 diabetes mellitus as a risk factor for stroke: the Framingham Offspring Study. Arch Intern Med 2006;166:106-111

24. Park HS, Song YM, Cho SI. Obesity has a greater impact on cardiovascular mortality in younger men than in older men among non-smoking Koreans. Int J Epidemiol 2006;35:181-187

25. Arboix A, Oliveres M, García-Eroles L, Maragall C, Massons J, Targa C. Acute cerebrovascular disease in women. Eur Neurol 2001;45:199-205

26. Aronow WS, Ahn C, Gutstein H. Risk factors for new atherothrombotic brain infarction in 664 older men and 1,488 older women. Am J Cardiol 1996;77:13811383

27. Wassertheil-Smoller S, Fann C, Allman RM, Black HR, Camel GH, Davis B, Masaki K, Pressel S, Prineas RJ, Stamler J, Vogt TM. Relation of low body mass to death and stroke in the systolic hypertension in the elderly program: the SHEP Cooperative Research Group. Arch Intern Med 2000;160:494-500

28. Waldstein SR, Katzel LI. Interactive relations of central versus total obesity and blood pressure to cognitive function. Int J Obes 2006;30:201-207

29. Elias MF, Elias PK, Sullivan LM, Wolf PA, D'Agostino RB. Obesity, diabetes and cognitive deficit: the Framingham Heart Study. Neurobiol Aging 2005;26 (Suppl. 1):11-16

30. Gustafson D, Rothenberg E, Blennow K, Steen B, Skoog I. An 18-year follow-up of overweight and risk of Alzheimer disease. Arch Intern Med 2003;163:15241528

31. Beydoun MA, Beydoun HA, Wang Y. Obesity and central obesity as risk factors for incident dementia and its subtypes: a systematic review and meta-analysis. Obes Rev 2008;9:204-218

32. Levine JA, Lanningham-Foster LM, McCrady SK, Krizan AC, Olson LR, Kane PH, Jensem MD, Clark MM. Interindividual variation in posture allocation: possible role in human obesity. Science 2005;28: 307:584-586

33. Koster A, Patel KV, Visser M, van Eijk JT, 
Kanaya AM, de Rekeneire N, Newman AB, Tylavsky FA, Kritchevsky SB, Harris TB; Health, Aging and Body Composition Study. Joint effects of adiposity and physical activity on incident mobility limitation in older adults. J Am Geriatr Soc 2008;56:636-643

34. Ortega-Alonso A, Sipilä S, Kujala UM, Kaprio J, Rantanen T. Body fat and mobility are explained by common genetic and environmental influences in older women. Obesity (Silver Spring) 2008;16: 1616-1621

35. Jensen GL, Friedmann JM. Obesity is associated with functional decline in community-dwelling rural older persons. J Am Geriatr Soc 2002;50:918-923

36. Barzilay JI, Blaum Carolina, Moore T, Xue QL, Hirsch CH, Walstom JD, Frird LP. Insulin resistance and inflammation as precursor of frailty: the Cardiovascular Health Study. Arch Intern Med 2007;167; 635-641

37. Launer LJ, Harris T, Rumpel C, Madans J. Body mass index, weight change, and risk of mobility disability in middle-aged and older women: the Epidemiologic Follow-Up Study of NHANES I. JAMA 1994; 271:1093-1098

38. Jenkins KR. Obesity's effects on the onset of functional impairment among older adults. Gerontologist 2004;44:206-216

39. Zizza CA, Herring A, Stevens J, Popkin BM. Obesity affects nursing-care facility admission among whites but not blacks. Obes Res 2002;10:816-823

40. Villareal DT, Banks M, Sinacore DR, Siener C, Klein S. Effects of weight loss and exercise on frailty in obese older adults. Arch Intern Med 2006;166:860-866

41. Cicuttini FM, Spector TD. Osteoarthritis in the aged: epidemiological issues and optimal management. Drugs Aging 1995; 6:409-420

42. Riedner CE, Rhoden EL, Ribeiro EP, Fuchs SC. Central obesity is an independent predictor of erectile dysfunction in older men. J Urol 2006;176:1519-1523

43. Saiqal CS, Wessells H, Pace J, Schonlau M, Wilt TJ. Urologic diseases in America Project: predictors and prevalence of erectile dysfunction in a racially diverse population. Arch Intern Med 2006;166:207212

44. Bacon CG, Mittleman MA, Kawachi I, Giovannucci E, Glasser DB, Rimm EB. Sexual function in men older than 50 years of age: results from the health professionals follow-up study. Ann Intern Med 2003;139:161-168
45. Larrieu S, Pérès K, Letenneur L, Berr C, Dartigues JF, Ritchie K, Février B, Alpérovitch A, Barberger-Gateau P. Relationship between body mass index and different domains of disability in older persons: the 3C study. Int J Obes Relat Metab Disord 2004:28:1555-1560

46. Hsu CY, Iribarren C, McCulloch CE, Darbinian J, Go AS. Risk factors for end-stage renal disease: 25-year follow-up. Arch Intern Med 2009; 169:342-350

47. Prospective Studies Collaboration, Whitlock G, Lewington S, Sherliker P, Clarke R, Emberson J, Halsey J, Qizilbash N, Collins R, Peto R. Body-mass index and cause-specific mortality in 900000 adults: collaborative analyses of 57 prospective studies. Lancet 2009;373:10831096

48. Chou CY, Lin CH, Lin CC, Huang CC, Liu CS, Lai SW. Association between waistto-hip ratio and chronic kidney disease in the elderly. Intern Med J 2008;38:402406

49. Flessner MF, Wyatt SB, Akylbekova EL, Coady S, Fulop T, Lee F, Taylor HA, Crook E. Prevalence and awareness of CKD among African Americans: the Jackson Heart Study. Am J Kidney Dis 2009; 53:238-247 